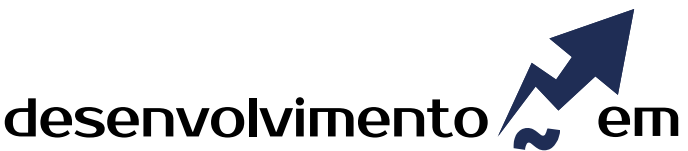 QUESTÃO
}

\section{Tecnificação de Produtores e Estruturas de Governança no Sistema Agroindustrial de Leite}

\author{
http://dx.doi.org/10.21527/2237-6453.2018.45.292-315 \\ Recebido em: $12 / 11 / 2016$ \\ Aceito em: $12 / 6 / 2018$
}

Daniela Caldas Acosta ${ }^{1}$, José Paulo de Souza², Sandra Mara Schiavi Bankuti

\begin{abstract}
RESUMO
As evoluções observadas na trajetória do Sistema Agroindustrial (SAG) do leite no Brasil refletiram no modo de operação e nas relações dos segmentos produtor e processador. Embora esse SAG apresente crescimento, a diversidade no nível tecnológico do segmento de produção rural tem efeito sobre o desempenho da cadeia de forma geral, e se estende para a estrutura das relações, impactando na distribuição de valor nas transações. Assim, a proposta no presente artigo é entender as estratégias de organização dos segmentos produtor e processador, que integram a cadeia produtiva do leite no estado do Paraná, dado o nível de especialização tecnológica dos produtores. Para tanto o seguinte objetivo foi definido: compreender como se dão as relações entre o segmento produtor e processador no SAG de leite ao se considerar o nível de especialização tecnológica dos produtores em diferentes regiões do Estado do Paraná. Procedimentos metodológicos sustentados em pressupostos qualitativos, e pesquisa descritiva envolvendo dados empíricos primários foram utilizados para o alcance desse objetivo. Os dados primários foram obtidos a partir de entrevistas semiestruturadas com produtores e processadores localizados nas diferentes regiões do Estado. Como resultado identificou-se uma estreita conexão entre o nível de tecnificação e as estruturas de governança. As estruturas de governança predominantes são de forma híbrida, envolvendo contratos formais e, em sua maioria, informais, requerendo confiança e reputação. Nesse caso, identificou-se que a contratação formal associa-se a níveis elevados de tecnificação no segmento de produção rural, sendo encontrada apenas na região Centro-Oriental do Estado, com elevada capacidade produtiva e melhor distribuição de valor. Já o contrato informal, com níveis menores de tecnificação e menores resultados predominam nas demais regiões do Estado.
\end{abstract}

Palavras-chave: Contratos. Atributos de transação. Dimensões mensuráveis. Direitos de propriedade.

\section{PRODUCERS' TECHNIFICATION AND GOVERNANCE STRUCTURES IN DAIRY AGRIBUSINESS SYSTEM}

\begin{abstract}
The developments observed in dairy milk Agribusiness System (AGS) trajectory in Brazil reflected in the operating mode and in the relations of the producer and processor segments. The diversity at the technological level of dairy rural production segment, in Brazil, had an effect on the general performance of the chain, extended to the structure of relationships, and impacting on the distribution of value in transactions. This aspect is explored in this article, grounded on the proposal to understand the organization strategies of the segments that integrate the production chain through the assumptions of Transaction Costs Economics and Measurement costs Theory. For this, we aimed at understanding how the relationship between the dairy producer and processor segments happens, when considering the level of technological specialization of producers in different regions of the state of Paraná. Methodological procedures based on qualitative assumptions and descriptive research involving primary empirical data were used to reach this objective. The primary data were obtained from semi-structured interviews with producers and processors located in different regions of the State. As a result, a close connection has been identified between level of technification and governance structures. Hybrid forms are the predominant governance structures, involving formal and mostly informal contracts. The latter requiring trust and reputation. In this case, it was identified that formal contracting is associated with high levels of technification in the rural production segment. This form was found only in the Central-Eastern region of the State, highlighting the high level of productivity and better distribution of value. On the other hand, informal constraints predominate in other regions of the state and are associated with low level of technification and low productivity.
\end{abstract}

Keywords: Contracts. Transaction attributes. Measurable dimensions. Property rights.

\footnotetext{
${ }^{1}$ Mestre e doutoranda em Administração pela Universidade Estadual de Maringá. acostadani@hotmail.com

${ }^{2}$ Doutor em Engenharia de Produção pela Universidade Federal de Santa Catarina. Professor da Universidade Estadual de Maringá. jpsouza@uem.br

${ }^{3}$ Doutora em Engenharia de Produção pela Universidade Federal de São Carlos. Professora da Universidade Estadual de Maringá. sandraschiavi@gmail.com
} 
O início dos anos 90 é considerado o ponto de ruptura na atividade leiteira no Brasil, em que algumas ações provocaram mudanças profundas na estrutura existente (JANK; FARINA; GALAN, 1999; ALVES, 2001; ALMEIDA, 2001; MADALENA, 2001; FERRARI et al., 2005; BANKUTI, 2007). Destacam-se entre essas ações: o fim do tabelamento do preço do produto; a abertura do setor à concorrência externa; a consolidação do Mercosul; a redução da inflação e a estabilização da economia. O despertar do setor para a competitividade provocou o crescimento do mercado, do consumo e das importações de lácteos (JANK; FARINA; GALAN, 1999).

Apesar do crescimento do mercado lácteo, contudo, o cenário também expôs problemas existentes no seu Sistema Agroindustrial (SAG), como: a qualidade inferior se comparada ao padrão internacional, no leite transacionado; a existência de uma legislação ultrapassada; uma ineficiente fiscalização sanitária da atividade, gerando um baixo nível de competitividade do leite.

Esses problemas, somados à questão da segurança alimentar e da saúde pública, desencadearam a necessidade de o governo estabelecer uma legislação que garantisse um padrão mínimo de qualidade ao processo produtivo. Isso ocorreu com a edição, pelo Ministério da Agricultura, Pecuária e Abastecimento (Mapa), das Instruções Normativas, n. 51/2002 e depois, a n. 62/2011, que substituiu a primeira. Essas normativas exigiram dos produtores e processadores a observância de uma série de critérios em relação à operação e manejo para a produção de leite, numa tentativa de melhorar e padronizar a qualidade do produto fornecido.

Esse regramento desencadeou uma busca por adaptação na forma de produzir o leite, e exigiu investimentos na modernização da infraestrutura nas propriedades, no melhoramento do plantel e no nível técnico dos produtores (MINISTÉRIO..., 2015). Como resultado, segundo o Instituto Brasileiro de Geografia e Estatística ? IBGE (INSTITUTO..., 2015), no decorrer das duas últimas décadas (até os últimos indicadores de 2014), ano após ano, o setor apresenta crescimento do rebanho leiteiro, de produção e de consumo.

Pode-se vislumbrar, porém, que, num país de dimensões continentais como o Brasil, cada região brasileira assimilou e se adaptou às mudanças exógenas do setor leiteiro em ritmos diferentes. Além disso, influenciaram também as características idiossincráticas regionais, como clima e topografia, questões culturais, sociais e econômicas dos agentes. Assim sendo, a influência do ambiente institucional formal convive com a variabilidade existente de práticas de conduta, crenças e tradições, características das restrições informais, que emergem, como descrito por North $(1990,1991)$, e constituem o ambiente institucional vigente nesse SAG. Esse ambiente constituído exerce influência nas ações dos agentes (WILLIAMSON, 1985), tanto no modo de produzir quanto no modo de transacionar seus ativos no mercado.

Segundo Okano, Vendrametto e Santos (2010), uma parcela significativa de produtores ainda mantém uma visão tradicional do negócio, apresentando barreiras culturais e resistência às mudanças, principalmente com relação à adoção de novas técnicas e tecnologia na atividade. Os autores observaram que a maioria desses produtores investe pouco em melhorias no processo produtivo, o que impacta no volume de leite produzido. Pelos dados apresentados pelo IBGE (INSTITUTO..., 2006) e Banco Nacional 
de Desenvolvimento Econômico e Social - BNDES (BANCO..., 2013), calcula-se que em 2006 mais de um milhão de produtores produziam menos de 50 litros/dia, do 1,3 miIhão existente.

O Paraná, não diferente das demais regiões ou Estados brasileiros, apresenta aspectos e fatores positivos e negativos para o SAG leiteiro. Além disso, o Estado possui uma das maiores bacias leiteiras em expansão, respondendo, em 2013, por cerca de $12 \%$ da produção do leite no Brasil, conforme relatório da Seab (SECRETARIA..., 2016). Nesse aspecto, o destaque é para o município de Castro, na região Centro-Oriental do Estado, com produção de 239 milhões de litros/ano, considerado o maior produtor de leite no Brasil (INSTITUTO..., 2015). Essa crescente trajetória do SAG do leite do Paraná vem se justificando pelos volumes produzidos, pela quantidade de produtores existentes e pelos números do rebanho bovino (SECRETARIA..., 2016).

Algumas pesquisas realizadas por órgãos públicos como o Mapa, Instituto Brasileiro de Geografia e Estatística (IBGE), Secretaria da Agricultura e do Abastecimento do Paraná (Seab) e Instituto Paranaense de Desenvolvimento Econômico e Social (Ipardes), entretanto, retrataram que no Estado há um grande número de produtores não especializados inseridos na cadeia do leite, que atuam em sua maioria no mercado informal (sem inspeção). O Ipardes (INSTITUTO..., 2010) estimou que esse montante de produtores informais pode chegar a 80\% dos 114 mil produtores do Estado. É de se pressupor, nesse caso, que a condição tecnológica desses produtores tem influência nas estruturas estabelecidas para realizar suas transações.

Dessa forma, ao se tratar das condições negativas observadas, sob amparo dos pressupostos teóricos da Economia dos Custos de Transação (ECT) e da Teoria dos Custos de Mensuração (TCM), focando-se em como esses arranjos se organizam e operam, a primeira indicação que se vislumbra é que o mercado informal para transações recorrentes significa regras e obrigações informais, impactando no desempenho do SAG.

Nesse aspecto, além do ambiente institucional envolvendo regramento e restrições, as microinstituições, no campo das relações entre os agentes, orientam as estratégias e ações que se amparam na busca de eficiência e impactam em seu desempenho. Esse é o campo de estudo da corrente denominada de Nova Economia Institucional que, assumindo as instituições para a coordenação dos mercados, desdobra-se em duas correntes: a ECT e a TCM. Essas vertentes mostram-se opções teóricas robustas para entender como se organizam e se relacionam os agentes para realizar suas trocas. Particularmente para o SAG de leite, diversos estudos já fundamentaram tal associação teórica, como: Jank e Galan (1999), Jank, Farina e Galan (1999), Madalena (2001), Ferrari et al. (2005), Campos e Piacenti (2007), Zoccal et al. (2008), Okano, Vendrametto e Santos (2010) e Carvalho et al. (2013).

Essas considerações teóricas, e as evidências empíricas da diversidade produtiva, tecnológica e competitiva no segmento produtor de leite no Estado do Paraná, contribuíram para a definição do problema de pesquisa que move este artigo, estruturado na seguinte questão: como se apresentam os arranjos que sustentam as transações envolvendo produtores especializados e não especializados no SAG de leite paranaense, ao se considerar as diferentes regiões produtoras? Assim, com fundamento no pressu- 
posto da eficiência, o objetivo estabelecido foi: compreender como se dão as relações entre o segmento produtor e processador, ao se considerar seu nível de especialização tecnológica nas diferentes regiões do Estado do Paraná.

Para alcançar esse objetivo o presente artigo estrutura-se apresentando, além desta introdução, uma seção apresentando os pressupostos teóricos que são utilizados para discutir as estruturas de governança e a função da mensuração nos estudos dos arranjos produtivos. Na sequência discute-se o SAG de leite no Paraná, na seção seguinte são apresentados os procedimentos metodológicos utilizados para a realização do trabalho empírico, em que se detalha as regiões pesquisadas e o sistema de coleta de informações. Na seção subsequente apresentam-se os dados e a análise dos resultados, que são organizados a partir dos pressupostos teóricos adotados. Por fim apresenta-se a conclusão e são indicadas as referências do trabalho.

\section{REFERENCIAL TEÓRICO}

\section{Estruturas de Governança para a ECT}

As estruturas de governança atuam na esfera das microinstituições e são capazes de adequar e coordenar as transações econômicas de acordo com suas características. Farina $(1999$, p. 150, 156) complementa essa definição de governança indicando que: "governar a transação significa incentivar o comportamento desejado e, ao mesmo tempo, conseguir monitorá-lo. [...] são resultado de uma construção dos agentes econômicos". Essa afirmação é convergente com as colocações de Williamson (1985, 1996, 2007), que a partir da proposição de Commons (1932) de tratar do problema da organização econômica tomando a transação como unidade de análise (substituindo preço e saídas, e suprimento e demanda), vê a governança como forma de gerar ordem, mitigar conflitos e realizar ganhos mútuos.

Ao se seguir a linha proposta pela Teoria dos Custos de Transação, com origem nos trabalhos de Coase (1937) e formalizados por Williamson (1985), fundamentado no contexto da eficiência, a estrutura de governança é definida de acordo com o potencial para geração de custos de transação (CROOK et al., 2013). Para isso considera-se as características do ambiente institucional e a estrutura de governança vigente, em virtude dos atributos da transação e dos pressupostos comportamentais, que se manifestam por ocasião da ocorrência de transações. Dessa forma, recai sobre as estruturas de governança o papel de coordenação desses determinantes da transação. Azevedo (2005) também se refere à eficiência com a qual a governança reage às mudanças do ambiente, e o quanto é capaz de se adaptar a elas. Isto é, para o autor, a própria governança deverá ter condições de avaliar sua adaptabilidade. Seguindo a proposição de Williamson (1985), da análise institucional comparativa, e não da magnitude dos custos de transação, Farina (1999) complementa que não há uma estrutura de governança superior, mas sim aquela que melhor se adapta à transação em questão. Por isso, a autora afirma que não é possível quantificá-la, sendo tão somente possível a identificação dos aspectos e problemas de coordenação.

Para a ECT a transação se define na concepção de Williamson (1985, p. 1, tradução nossa) como sendo "[...] o evento que ocorre quando um bem ou serviço é transferido através de uma interface tecnologicamente separável". Então, para que as transações 
da firma não se tornem onerosas nessa transferência, justifica-se que as transações econômicas devem ser coordenadas por estruturas de governança e alinhadas a elas. Esse alinhamento, para Williamson (1985), é a capacidade que as estruturas de governança possuem para prever como uma ou outra transação se desenvolverá. Essa natureza preditiva poderá ser determinada quando são conhecidos os atributos e os pressupostos comportamentais de cada transação realizada. Para a ECT os atributos da transação são identificados como: especificidade dos ativos, frequência e incerteza e os pressupostos comportamentais são a racionalidade limitada e o oportunismo (WILLIAMSON, 1985, 1996).

Desse modo, na busca da eficiência nas transações, diferentes configurações de governanças podem ser nelas encontradas, entre os três tipos oferecidos por Williamson (1985, 1996): mercado, híbrida (contratação) e hierárquica. Para o autor, a presença de ativos de elevada especificidade, de incertezas e recorrência na transação leva a transação para a integração vertical, dada a possibilidade de comportamento oportunista. A ausência desses atributos indica o mercado como estrutura de governança mais adequada, ficando a forma híbrida como forma intermediária. Segundo Zylbersztajn e Giordano (2015), tudo está ligado: a garantia de direitos sobre os valores gerados na produção dos ativos demanda instituições eficientes, que aliadas aos agentes também possibilitam a geração de incentivos para a atividade em questão. Para os autores, a partir desses aspectos podem surgir, igualmente, estruturas de governança mais eficientes e alinhadas ao sistema produtivo. Neste contexto, os agentes econômicos tendem a adotar as coordenações mais apropriadas a seus interesses, de forma a minimizar custos de transação (CROOK et al., 2013).

Destaca-se que a governança de mercado é caracterizada pelas transações de curto prazo, em que as partes não importam, ou seja, a identidade dos agentes não é requerida (WILLIAMSON, 1985, 1996). Na governança hierárquica, também chamada de governança unificada ou integração vertical, a firma assume a coordenação das transações que lhe são importantes, condição lhe dá o controle de ambos os lados da transação, permitindo ajustes rápidos. Assim, a integração vertical ocorre "na medida em que as transações se tornam progressivamente mais idiossincráticas" (WILLIAMSON, 1985, p. 69). Na forma híbrida a função é proteger os ativos de uma possível apropriação de valor e do hold-up (quebra contratual por apropriação de valor dos ativos específicos de uma parte sobre a contraparte num contrato (KLEIN, 1999)). Esse último tipo de governança é também caracterizado por contratos (AZEVEDO, 2000; ZYLBERSZTAJN, 2005a). Zylbersztajn (2005a) menciona que, no ambiente dos SAGs é comum os arranjos institucionais coordenarem as transações por meio de contratos e acordos.

Williamson $(1985,1996,2007)$ associa a questão contratual e os custos de transação com a eficiência das estruturas de governança adotadas. O autor faz o seguinte esclarecimento: "a abordagem proposta adota uma orientação contratual nas transações, a mesma sustenta que qualquer questão que possa ser formulada como um problema contratual pode ser investigado com vantagem em termos de economia de custos de transação" (1985, p. 17, tradução nossa). Na perspectiva da ECT, portanto, a firma é um "nexo de contratos", idealizada como "arranjo institucional" capaz de governar as tran- 
sações por meio desse instrumental, que podem ser contratos formais (sujeitos às leis) ou acordos informais (garantidos por salvaguardas e outros mecanismos) (ZYLBERSZTAJN, 2005a).

Com relação à atuação das governanças existentes nos sistemas agroindustriais, Caleman, Sproesser, Zylbersztajn (2008) evidenciam que a coordenação é uma questão-chave nos SAGs. Para eles, a coordenação resulta da relação conjunta dos agentes na tentativa de convergir seus interesses próprios aos do ambiente institucional em que estão inseridos, por meio da gestão (eficiente) dos arranjos e em prol do desenvolvimento da cadeia.

\section{Mecanismos de Controle da TCM}

$\mathrm{Na}$ TCM os mecanismos de controle (enforcement), a priori, teriam a mesma função das estruturas de governança na ECT, ou seja, também coordenar as transações econômicas. Na lógica da TCM, porém,, que se ampara também na Property Rights Theory, essa troca precisa ser controlada por um mecanismo que impeça a dissipação do valor do ativo e o proteja da apropriação indevida. Nesse caso, considera-se que a propriedade e o direito legal importam e a transação ocorre pela realização de transferências de direitos de propriedade entre os agentes. No pensamento de Barzel (1982, 2001, 2005), as organizações e seus agentes sempre estarão à procura da forma mais adequada de maximizar o valor da transação ao transferir seus direitos de propriedade, sendo assim mais eficientes nas trocas. Esse racional de eficiência ocorre por meio da mensuração das dimensões do ativo, cujo mal- delineamento tem como consequência a perda de direitos por uma das partes. Nesse aspecto, Foss e Foss (2001) sugerem que o atributo ou a dimensão dos ativos apresentam-se como a unidade de análise fundamental na ECM.

Segundo Barzel $(1982,2005)$, para organizar as trocas diferentes mecanismos de controle podem ser utilizados, em razão das informações disponíveis. O autor, em 2005, discute os seguintes mecanismos de controle, que podem assegurar as transferências de direitos numa transação: caveat emptor (relações de risco), leilões, relações contratuais, relações de longo prazo, múltiplos enforcers, integração vertical.

Os mecanismos caveat emptor (risco do comprador) e leilões são realizados no mercado e assumem que as trocas são efetivadas em uma situação de risco, em que as dimensões do produto são mensuradas superficialmente no momento da negociação, podendo ocorrer por amostragem. Assim, no sistema caveat emptor o comprador dispõe de algumas informações disponíveis do produto, e só poderá conferir as demais dimensões ao fazer uso dele. Nesse ponto, Barzel (2005, p. 360, tradução nossa) alerta: "[...], mas, então, a transação já não pode ser desfeita". No caso dos leilões o raciocínio é similar, o preço mínimo é estabelecido pelo vendedor, se houver apenas um comprador ele pagará este máximo. Outrossim, caberá aos compradores decidirem a otimização de seus lances, se tiver sido realizada uma pesquisa anterior e as ofertas forem menores, esse esforço (recursos) foi desperdiçado, gerando custos de transação (BARZEL, 2005).

As relações contratuais são formatadas de acordo com os atributos mensurados pelas partes (comprador e vendedor) e podem ser controladas pelo Estado. Quanto menor for o custo da mensuração do atributo transacionado, melhor será que a transação seja realizada por meio de contratos (BARZEL, 2001, 2005), pois poderá ser garantida por uma terceira parte. Segundo Barzel $(2001,2005)$ os problemas de aplicação do con- 
trato surgem quando são incompletos, com os direitos de propriedade mal-delineados. Para o autor, isso depende de dois fatores: o custo de mensuração dos atributos do ativo e a natureza da execução. Quanto mais baixo o custo para mensurar as dimensões do ativo, mais clara sua delimitação e mais fácil a aplicação de sua propriedade. Cabe ressaltar que o Estado não participa do processo contratual, somente dá respaldo às salvaguardas contratuais em caso de disputas, todavia as informações com as quais o Estado fará valer a transação são apenas aquelas constantes nos termos do próprio contrato, que se tornam os direitos de propriedade legais.

Nas relações de longo prazo o vendedor faz implícitas ou explícitas promessas acerca do nível de certos atributos de seu commodity (BARZEL, 2005). Dessa forma, para o comprador, a informação passa a ter um custo menor do que se fosse mensurada anteriormente à transação. Por conseguinte, para o início da operação o comprador considera fatores como reputação e confiança (BARZEL, 1982). Então o vendedor, ao fazer promessas acerca dos atributos de seu ativo, permite ao comprador abster-se de realizar a mensuração dos atributos no ato da compra.

Em todo caso, o fato de não inspecionar o ativo define para o comprador o possível risco de perda, sua garantia fica por conta da reputação, ou pela força da marca do vendedor (valor agregado). Sobre isso, Barzel (2002, p. 360, tradução nossa) conclui: "Quanto mais o vendedor poderia ganhar por quebrar sua promessa, mais fortes as relações de longo prazo devem ser, e maior é o investimento feito nelas". Barzel (1997, 2001) caracteriza esses direitos de propriedade como econômicos, em que o próprio agente tem condições de garantir por meio do acordo realizado. Nessa perspectiva, o comprador poderá conferir as dimensões ex post à transação e, em caso de insatisfação, poderá somente cancelar compras futuras, uma vez que não está garantido por um contrato formal. 0 autor, em 2005, ratifica que relações de longo prazo exigem investimento, enquanto a garantia por contrato exige a presença do Estado e a regra da lei, e sua presença simultânea (múltiplos enforcers) implica a eliminação do risco moral (relação de longo prazo) e necessidade de capital reputacional (contrato).

A integração vertical, para Barzel (2001, p. 9, tradução nossa), "é um estado em que o reclamante residual da firma, ou alguma outra organização, toma para si mesmo a variabilidade de duas ou mais operações verticais combinadas". A integração vertical é útil para superar as dificuldades de transferência de direitos de propriedade, por conta de ativos de difícil mensuração (BARZEL, 2002). A partir dessa constatação a TCM prevê que quando os direitos de propriedade não são claramente definíveis, e existe a possibilidade de sua apropriação, a decisão de integrar verticalmente torna-se uma opção a ser considerada. Dessa forma a organização terá a posse total dos direitos econômicos dos ativos de difícil mensuração (BARZEL, 2002).

Cabe observar que, assim como na ECT, na TCM as questões como a racionalidade limitada e a incerteza podem resultar em situações de apropriação de direitos (BARZEL, 1997), ou como sugerido por Zylbersztajn (2005b), um comportamento oportunista implícito das partes na relação. Barzel (2005, p. 368, tradução nossa) explica da seguinte forma:

Quando a mensuração tem baixo custo, escrever e garantir uma contratação é trivial, e a propriedade é bem definida. Nem quase-renda oriunda de ativos específicos nem nada será capturado. Entretanto, a mensuração é custosa e sujeita a erros, 
e os agentes não têm certeza de como serem justos nas suas trocas, seus direitos econômicos não são bem definidos. Captura oportunista existe em todo lugar, e os agentes usarão recursos para capturar o que puderem. Esse comportamento caracteriza disputa [...].

Assim, essas orientações teóricas (estruturas de governança na ECT e mecanismos de controle na ECM) indicando porque algumas organizações decidem produzir internamente e outras optam por contratar no mercado, nortearam as análises nas relações envolvendo produtor e processador no SAG do leite no Paraná. Nota-se que os aspectos de especificidade dos ativos e de garantia dos direitos de propriedade, indicando potenciais custos de transação ex ante ou ex post, são discutidos sob a consideração do nível de especialização dos produtores, em alinhamento à proposta do estudo.

\section{EVOLUÇÃO DO SAG DO LEITE NO BRASIL}

O Brasil é considerado o sexto maior produtor mundial de leite, segundo a Usda (UNITED..., 2015). Em 2014 produziu cerca de 35,1 bilhões de litros, conforme dados do IBGE (INSTITUTO..., 2015). Neste mesmo ano informações publicadas pela MilkPoint (2016) apontaram que a aquisição de leite in natura, por estabelecimento sob inspeção sanitária, foi de 24,7 bilhões de litros, demonstrando que, em nível de Brasil, a produção informal de leite (não adquirido por processadores inspecionados) ficou abaixo dos $30 \%$ da produção. Esse fato demonstra, na análise de Ribeiro (2016), que as mudanças sofridas pelo SAG, nas últimas décadas, realmente influenciaram na evolução e no desenvolvimento econômico da atividade leiteira, dado que, em 1997, esse percentual era de $42,8 \%$.

Na busca por esses melhores resultados, em 2011 foi editada a Instrução Normativa n. 62 (MINISTÉRIO..., 2011), que substituiu a Instrução Normativa n. 51. Essa Instrução buscou conferir maior foco nos parâmetros de qualidade do leite, visando a garantir um produto mais nutritivo e competitivo comercialmente (DÜRR, 2012). Isso seria obtido pela exigência de mensuração da qualidade do leite, por testes e análises, já na coleta do produto. Nesse aspecto a IN 62 passou a estabelecer a verificação: das dimensões físicas (temperatura, acidez, entre outras); das dimensões microbiológicas (presença de água e antibiótico, contagem bacteriana total - CBT - e contagem de células somáticas - CCS); das dimensões químicas (gordura, proteína e sais minerais). A norma também prevê que cabe ao processador fiscalizar esses parâmetros junto aos produtores com os quais transaciona, e ao governo cabe fiscalizar os processadores (nos âmbitos federal, estadual ou municipal). A instituição da IN 62, no entanto, ainda não garantiu a adesão de todos os produtores na padronização das propriedades. Segundo o Mapa (MINISTÉRIO..., 2015), entre os principais motivos para a baixa adesão destacam-se a falta de conhecimento e a instrução com acompanhamento técnico aos produtores.

Identifica-se, assim, a importância dos aspectos institucionais, nos termos descritos por North (1991), notadamente quanto às restrições formais, para obtenção de meIhores resultados no SAG. Avançando, ainda, na proposição de North (1991), quando se considera as restrições informais, existem padrões de conduta institucionalizados nas transações envolvendo produtores e processadores. Um exemplo é o uso de referenciais de preço e cotações para o leite. Esses valores são extraoficiais, definidos por entidades públicas e privadas, que pesquisam e analisam o mercado lácteo. Foram mencionados 
na pesquisa o Conselho Paritário Produtores/Indústrias de Leite do Estado do Paraná (Conseleite-Paraná) e o Centro de Estudos Avançados em Economia Aplicada/USP (Cepea) como referências para obtenção de preço. Evidenciou-se que muitos produtores e processadores baseiam suas negociações e renegociações nesses valores. Isso parece ser um indicador de que as estruturas de governança no SAG são orientadas pela busca de flexibilidade e adaptação na coordenação das relações e transações no ambiente institucional do SAG, considerando as orientações formais e informais, públicas e privadas.

Destaca-se que, desde a década de 40, devido ao tabelamento, ocorreu um desestímulo de muitos produtores em modernizar tecnologicamente a produção de leite. O mercado lácteo, contudo, não ficou na mais completa estagnação; lentamente algumas inovações tecnológicas foram sendo incorporadas ao processo produtivo, como: a embalagem descartável, o transporte do leite em tanques refrigerados, a ultrapasteurização, o resfriador a granel nas propriedades (JANK; FARINA; GALAN, 1999) e, principalmente, o lançamento do leite UHT, pelo segmento processador. Segundo Alves (2001), a entrada e aceitação do mercado consumidor do leite UHT representou um crescimento de $415 \%$ nas vendas. Jank e Galan (1999, p. 210) oferecem a seguinte visão deste panorama: "uma guerra de preços sem precedentes [...], principalmente no grande varejo, que transformou o longa vida no produto regulador do mercado de leite". A possibilidade de ter maior tempo de validade e de estocagem proporcionou um aumento no volume produzido, e também da expansão dos limites do mercado, eliminando as barreiras regionais para as transações. O leite, além de "longa vida", também podia agora ser de "longa distância", expandindo sua cadeia, inclusive para a exportação.

Toda essa movimentação, entretanto, não foi acompanhada na sua totalidade pelo segmento produtor, pois para um produtor se tornar especializado a tarefa demandava incentivos e investimentos financeiros para a melhoria do rebanho (genética, nutrição e bem-estar) e modernização da propriedade (equipamentos e infraestrutura) (JANK; GALAN, 1999). Para muitos produtores a renda adquirida pela produção não comportaria os investimentos realizados (MADALENA, 2001). Ademais, o último censo agropecuário do IBGE, de 2006, mostrou que somente $22 \%$ das 1,35 milhão de propriedades leiteiras tinham acesso à assistência técnica especializada. Segundo estatísticas do Mapa (MINISTÉRIO..., 2015), cerca de 450 mil produtores deixaram a atividade entre os censos de 1996 (1,8 milhão de produtores) e 2006 (1,35 milhão de produtores) (INSTITUTO..., 2006). Os motivos, segundo essas pesquisas, são os mesmos: falta de capital, falta de conhecimento do produtor e ausência de acompanhamento técnico. Como consequência dessas dificuldades observa-se uma baixa produtividade, qualidade e rentabilidade, que leva à desistência do produtor de permanecer na atividade (MINISTÉRIO..., 2015).

A falta de ação institucional para estabelecer um crescimento homogêneo, principalmente no segmento de produção rural, levou à convivência de dois grupos de produtores, aqueles especializados e aqueles não especializados. Jank e Galan (1999) explicam que o produtor especializado é aquele que se dedica a uma atividade principal, obtida a partir de investimentos especializados e outros ativos específicos para este fim, como know-how, tecnologia, economias de escala e diferenciação do produto. Já o não especializado, também chamado de "extrator" ou "extrativista", é o produtor que trabalha com tecnologia rudimentar, tem baixo conhecimento técnico da atividade e, por 
isso, de forma irregular vende seus produtos no mercado, mas não é capaz de suportar grandes oscilações de preços (JANK; GALAN, 1999; CARVALHO et al., 2013; MINISTÉRIO..., 2015).

Para o SAG do leite, portanto, as posições de Jank, Farina, Galan (1999), ainda se mantêm, pois a evolução tecnológica não confirma o desenvolvimento linear do sistema produtivo, mostrando uma irregularidade tecnológica. O desafio das estruturas de governança, que para esses autores é coordenar eficientemente diferentes níveis de tecnificação, com a quantidade e a qualidade do leite que o mercado exige nas suas transações, da mesma forma, ainda está presente para os agentes.

Observa-se, entretanto, que a forma como os eventos tecnológicos e legais evoluíram ao longo do tempo provocaram mudanças no perfil dos agentes e no porte dos segmentos das cadeias existentes, alterando seu modus operandi. Zylbersztajn e Giordano (2015, p. 248) explicam que no contexto agrícola, as transações tendem a se adequar à qualidade apresentada nos produtos transacionados no processamento, que gera padrões mais rígidos para a produção rural. Nesse raciocínio, pode-se considerar que o aumento do consumo pela população levou à necessidade de investimentos na produção, fato que, para o produtor, tornou o ato de negociar mais custoso. Conforme sugerem as abordagens da NEl, o desempenho econômico das sociedades resulta sempre das suas dinâmicas institucionais (NORTH, 1990). Nessa lógica, o SAG do leite incorporou mais inovações ao processo e ao produto, promovendo novas articulações nas coordenações existentes. Para um maior entrosamento e aproximação de produtores e processadores, todavia, é necessário firmar relações bilaterais, mais eficientes, menos custosas e mais duradouras (ZYLBERSZTAJN, 2005a) que a governança mercado.

Isso foi, de certa forma, observado nas transações do leite UHT. Nessas operações, grandes quantidades de leite eram negociadas entre produtores e processadores. As transações exigiam frequência e recorrência (WILLIAMSON, 1985), portanto deveriam ser amparadas por relações contratuais mais complexas que as usuais. O processador, por meio desses acordos e contratos, garantia o abastecimento de grandes varejistas (supermercados), que, garantidos, também contratavam volumes maiores. Essa realidade superava, em muito, a do leite pasteurizado que era comercializado em sacos plásticos, distribuído em pequenas quantidades diárias e de alta perecibilidade (ALVES, 2001). Desse modo, firmaram-se os contornos do SAG do leite, que retratava a atividade como uma cadeia produtiva, e o valor gerado nela passou a interessar setores de capital e tecnologia.

Assim, no contexto de uma cadeia, a forma de coordenar os elos existentes pode resultar em maior ou menor crescimento do SAG, ou mesmo na exclusão de produtores e processadores, que não apresentassem um nível aceitável de conformidade aos padrões exigidos pelo mercado (ZYLBERSZTAJN; GIORDANO, 2015). Nesse aspecto, Okano, Vendrametto e Santos (2010) evidenciaram que, no caso do leite, o perfil tradicional de alguns produtores resultou em resistência a mudanças, levando a um "desbalanceamento" de produtividade no SAG. Por outro lado, concluem, os produtores que modernizaram suas propriedades para atender à demanda, conseguiram se adaptar, coordenando melhor a relação produção e custos e promovendo desenvolvimento no SAG. 
Ainda assim, o BNDES (BANCO..., 2013) apontou duas características do leite que têm impacto sobre o desenvolvimento da atividade e sobre as relações de compra e venda do produto: a homogeneidade e a perecibilidade. Na primeira, identificou-se que a maioria dos produtores tem baixa capacidade de diferenciar o leite que produz, o que os torna dependentes da relação com o processador, que precisa assegurar a qualidade do leite adquirido. A perecibilidade do produto, por sua vez, impõe que o leite seja transportado quase diariamente, e refrigerado, até o laticínio. Nessas condições, cabe à estrutura de governança o papel de coordenar a transação dentro do curto prazo de validade do produto, garantindo mensuração da qualidade e direitos de propriedade com menos custos de transação. Essas duas características (homogeneidade e perecibilidade) elevam o nível de necessidade de coordenação, demandando estruturas de governança mais sofisticadas do que os mecanismos de mercado. Isso ratifica as colocações de Jank, Farina, Galan (1999), que alertaram que à medida que as especificidades do leite aumentassem a governança que iria predominar no SAG era a contratual.

Nota-se ainda que, segundo o Mapa (MINISTÉRIO..., 2015), a produção de leite no Brasil é realizada $95 \%$ por pequenos produtores e $5 \%$ por grandes produtores. Em termos de volume produzido, porém, a balança responde com outros números, pois $53 \%$ do leite é produzido pelos grandes produtores e $47 \%$ pelos pequenos produtores. Nesse raciocínio, considera-se que o desafio das estruturas de governança que atuam no SAG está em coordenar a produção dos $95 \%$ de pequenos produtores, atuantes num SAG regulamentado, modernizado e competitivo.

\section{PROCEDIMENTOS METODOLÓGICOS}

Os procedimentos aplicados neste artigo têm natureza qualitativa. O tipo de pesquisa utilizado foi a descritiva. Também foi usado o método indutivo para a análise, tendo em vista a extensão territorial do Paraná e a grande concentração de produtores e processadores de leite atuantes na atividade. Segundo Richardson (2012), o uso do método indutivo fundamenta-se nos fatos observados para se construir um raciocínio e se chegar a uma conclusão geral. O corte do tempo foi transversal, priorizando os arranjos econômicos existentes no tempo presente da pesquisa

O levantamento dos dados empíricos primários foi realizado por meio de pesquisa de campo, envolvendo a coleta de informações primárias durante o segundo semestre de 2015. Procurou-se abranger todas as regiões do Paraná, no intuito de coletar uma quantidade de dados suficiente para responder ao objetivo proposto. Foram realizadas entrevistas nas propriedades rurais, cooperativas, associações rurais, empresas e em evento do setor lácteo, sendo guiadas por roteiros de questões. A Figura 1 indica no mapa do Estado do Paraná as regiões, objeto do estudo em que ocorreu a coleta dos dados, e o Quadro 1 relaciona todos os entrevistados de acordo com a região correspondente, bem como a indicação do nível de concentração de produtores e processadores por região. 
Figura 1 - Mapa das regiões do Paraná pesquisadas

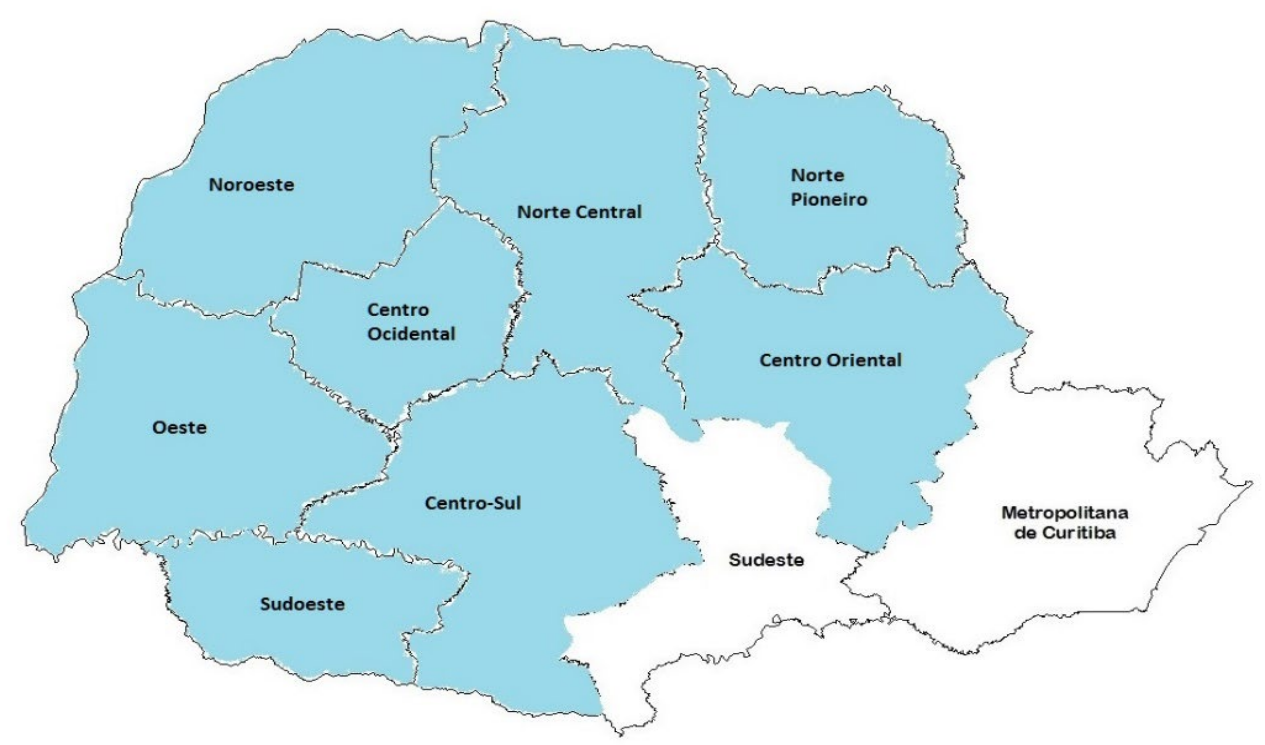

Fonte: Adaptado de INSTITUTO..., 2010.

Os dados foram coletados por meio de entrevistas semiestruturadas, realizadas com produtores e processadores de leite. Nos produtores, a maioria das entrevistas foi realizada com os proprietários ou sócios das propriedades, entrevistando-se apenas um arrendatário. Os entrevistados (numerados e identificados de 1 a 31) foram selecionados considerando-se sua região de inserção, de forma não proposital, a partir de dados disponíveis em associações e laticínios e indicação de outros produtores. As entrevistas tiveram duração em média de uma hora e dez minutos, foram gravadas e transcritas e arquivadas em meio eletrônico. Embora não houvesse a preocupação com o número de entrevistas, mas com a qualidade da informação, foram ouvidos produtores em todas as regiões, de forma a identificar especificidades associadas ao objetivo estabelecido.

Já os processadores (numerados de1 a 8) foram selecionados pela representatividade nas regiões estudadas. Foram entrevistados, por cerca de duas horas, os proprietários dos laticínios e, nas cooperativas e indústria, o presidente, gerentes e supervisores responsáveis pelo setor de lácteos. Essas entrevistas também, foram gravadas transcritas e armazenadas em meio eletrônico.

Quadro 1 - Descrição dos produtores e processadores de leite entrevistados por região

\begin{tabular}{|c|c|c|}
\hline \multirow{2}{*}{ REGIÕES } & \multicolumn{2}{|c|}{ SEGMENTOS } \\
\cline { 2 - 3 } & Produtores & Processadores \\
\hline Norte Central; Norte Pioneiro & 3 & - \\
\hline Noroeste & 7 & 3 laticínios \\
\hline Centro Ocidental & 3 & 1 laticínio \\
\hline Oeste; Sudoeste & 6 & $\begin{array}{c}\text { cooperativa e } 1 \\
\text { indústria }\end{array}$ \\
\hline Centro-Oriental & 4 & 1 cooperativa \\
\hline Centro-Sul & 8 & 1 cooperativa \\
\hline
\end{tabular}

Fonte: Elaborado pelos autores a partir dos dados primários. 
O levantamento dos dados secundários foi realizado por pesquisa documental e pesquisa bibliográfica, disponíveis em meios eletrônicos e impressos. Foram utilizados para tanto publicações acadêmicas, artigos científicos e estatísticas do setor leiteiro, provindos de organizações públicas e privadas, como universidades, Ministério da Agricultura, Pecuária e Abastecimento (Mapa), Instituto Brasileiro de Geografia e Estatística (IBGE), Secretaria da Agricultura e do Abastecimento do Paraná (Seab), Instituto Paranaense de Desenvolvimento Econômico e Social (Ipardes), U.S. Department of Agriculture (USDA) e sites de referência para produção leiteira.

Após o levantamento dos dados primários (gravados e transcritos) e dos secundários, todos foram analisados de forma comparativa à revisão teórica. Para isso, as informações foram categorizadas, considerando-se a teoria proposta e outros influenciadores que surgiram durante as entrevistas, como o nível de tecnificação, e interpretadas pelo Método de Análise de Conteúdo (BARDIN, 1979), com vistas a atender ao objetivo proposto.

\section{APRESENTAÇÃO DOS DADOS E ANÁLISE DOS RESULTADOS}

\section{As Estruturas de Governança no SAG do Leite Paranaense na Ótica da ECT e TCM}

A lógica que orientou a evolução do SAG do leite brasileiro, discutido anteriormente, também se aplica ao SAG do leite no Paraná. No Paraná, entretanto, essa evolução segue configurações particulares, como na forma de negociar e no modo de firmar relações, a começar pelo nível de especialização dos produtores atuantes e especificidades regionais. Assim, parece lógico que haja no SAG paranaense desenhos e contornos diferentes nos seus arranjos e relações. Assim, com o foco direcionado para produtores e processadores e nas transações que resultam de suas relações, buscou-se expor como as relações se configuraram nas suas microrregiões. Considerou-se a presença de informalidade nas negociações praticadas via mercado, a efetividade das contratações bilaterais (formais e informais) e uma possível governança hierárquica nas propriedades leiteiras, ainda que futura.

O trabalho de campo, nesse SAG, que buscou dados primários a partir do posicionamento de produtores e processadores, indicou a presença da governança híbrida, envolvendo contratações formais e acordos informais. Esse reconhecimento permitiu que se entendesse como se dá a dinâmica relacional entre os agentes e a avaliação da condição de alinhamento obtido, tomando-se como referência os atributos de transação (ECT) e as dimensões transacionados (TCM). Além disso, esse fato confirma a análise de Zylbersztajn (2005a), que ressalta que a Teoria da Firma também está presente no meio agrícola e se sobressai quando são analisadas as relações contratuais existentes nesse meio.

Quanto à classificação de produtores, em especializados e não especializados, indicada por Jank e Galan (1999), o trabalho empírico destacou que essa classificação não parece oferecer um adequado posicionamento dos produtores. A pesquisa de campo esclareceu que, a partir do advento da IN 62, os produtores não especializados não poderiam fazer parte do mercado formal do leite, por não apresentarem o padrão mínimo 
de qualidade exigido por esse regramento. Por outro lado, todos os demais produtores não poderiam ser enquadrados como especializados, pois apresentavam diferenças nessa especialização.

Assim, considerou-se que a classificação por nível de tecnificação (baixo, médio e alto), relativo aos investimentos específicos realizados na produção, daria melhor indicação do nível de capacidade e participação do produtor no SAG. Enquanto que o uso de animais mestiços, manejo básico e uso de tecnologia mínima visando a atender às normas legais caracterizam, em um extremo, produtores de baixa tecnificação, no outro extremo encontram-se produtores que utilizam raça pura e melhoramento genético, manejo individualizado e amparado em alta tecnologia em termos de infraestrutura e produção. No meio-termo estão os produtores de média tecnificação que, embora não estejam na ponta tecnológica utilizam animais puros, um manejo avançado e tecnologia compativel.

Quanto às estruturas de governança, para os processadores entrevistados, o ambiente institucional mostrou-se influenciador da predominância da governança híbrida nas relações. Foi identificado que os processadores procuram não adquirir leite de produtores desconhecidos, mesmo em situações adversas, por questões de qualidade e logística. Por outro lado, houve relatos indicando que podem, ocasionalmente, negociar sobras de produção com outros processadores, quando ocorre algum problema com o fornecimento de seus produtores. O Processador 3 , da região Norte, alegou que essa situação pode acontecer, o que o obriga a recorrer ao mercado para suprir a falta de matéria-prima. O entrevistado afirmou: "Pode ocorrer de comprar leite de outros processadores; compro aproximadamente 5.000 litros/semana para aproveitar o frete, são as sobras deles". Dessa forma, o laticínio tem garantias de que o leite comprado no mercado spot está apto para o uso, possivelmente não havendo adulteração ou contaminação, uma vez que o outro laticínio já realizou os testes no leite. Sua viabilidade, porém, em termos de custos, só é considerada ocasionalmente. Ademais, isso indica que relações horizontais também se apresentam na cadeia.

Da mesma forma, no contexto atual, segundo os processadores, é inviável a forma hierárquica de governança. Para eles a integração vertical é inviabilizada pelo dispêndio de recursos necessários para custear, juntas, produção e fabricação. Isso porque a produção do leite tipo " $A$ " (produzido, beneficiado e envasado na propriedade) como determina a IN 62, sofre "rigorosa inspeção". Na pesquisa somente o Processador 4, no Noroeste do Paraná, operava nessas condições há mais de 20 anos, porém o proprietário revelou já no início da entrevista que aguardaria o final do ano para encerrar as atividades. Segundo ele, os motivos para tal decisão são a forte concorrência, o baixo preço do litro de leite no mercado e a possibilidade de obtenção de uma maior renda com o loteamento imobiliário da área da granja. Dessa forma, o regramento estabelecido, se de um lado, favorece a mensuração, justificando a forma híbrida, ao se considerar as proposições de Barzel (2005); de outro impõe condições para a integração vertical, notadamente formalizando a especificidade locacional para a transação (leite tipo A), o que ratifica o racional proposto por Williamson (1985) e limita esse movimento.

Constatou-se, portanto, que, para os processadores, é a forma híbrida de governança que gera menores custos de produção e transação, e que, independentemente da relação firmada, contrato formal ou informal, certas garantias dos direitos de pro- 
priedade na transação são obtidas. Essas garantias, em parte, são devidas à legislação vigente (IN 62), cujo regramento reduz os custos de mensuração e resolução de conflitos, ratificando North $(1990,1991)$, Williamson (1985) e Barzel (2005). Outra grande parte justifica-se pelas regras institucionalizados que predominam no ambiente, como o preço praticado no leite, fortemente influenciado pelos valores referenciais do Conseleite e Cepea, que levam a uma estabilização na relação, ratificando a função das restrições formais e informais propostas por North $(1990,1991)$. Assim, a regulamentação pública diminui o risco de perdas na transação e do comportamento oportunista por apropriação, e uma vez firmada a transação, os produtores só podem fornecer leite dentro do padrão exigido. O valor de referência, por sua vez, assegura um preço a ser pago, evitando renegociações e disputas entre as partes, ou seja, custos ex ante e ex post à transação.

Nas entrevistas com produtores ratificou-se que a escolha da governança híbrida predomina na coordenação das relações, em que se define os termos da relação com o processador, amparada no preço-base. Para o produtor a governança de mercado é inviável devido aos atributos da transação presentes, como a especificidade temporal do leite, que apresenta alta perecibilidade, e a necessidade de recorrência da relação, com frequência na coleta do leite, que se realiza, pelo menos, a cada dois dias. Essa constatação confirma a proposição de Williamson (1985) da avaliação institucional comparativa, bem como considera que o suporte das relações de mercado (credible commitment) se apresenta (WILLIAMSON, 2007). Da mesma forma, os produtores indicaram a inviabilidade da governança hierárquica. Para eles não há incentivo de políticas públicas para integralizar a produção de leite, devido aos altos custos de instalação e operação e o baixo preço do produto (a produção de leite tipo A exige o processamento na propriedade).

Sobretudo, tem-se que a adoção da governança híbrida nas relações, de maneira geral, não acarreta custos de transação elevados ex ante, mantendo-se a posição de Pondé, Fagundes e Possas (1997), por conta da facilidade de se contratar e efetivar a transação do leite. Destaca-se que, para a maioria dos produtores, o comprador apenas menciona verbalmente as condições e exigências. A coleta inicia-se imediatamente após o acordo do preço e do volume produzido ser firmado. Isso, muitas vezes, é definido somente por telefone, posto que na transação a mensuração é prática corrente, e os padrões para a transação já estão dados. Os custos ex post, pelos moldes da ECT, nessa relação podem ser ocasionais, e estão relacionados à busca de renegociação devido a causas como: erros de medições no leite coletado; descontos e atrasos nos pagamentos; falta de pagamento de adicionais predefinidos; renegociações de preço em função de quantidade e qualidade. Isso é exemplificado pela fala do Produtor 18: "Já deu CBT alto, e foi descontado, mas pelo histórico bom, a produção foi paga após reclamação, porque acha que foi erro na coleta. Não teve como fazer a contraprova".

As entrevistas permitiram indicar um alinhamento entre ambiente macro e microinstitucional por regiões do Estado do Paraná. O Quadro 2 apresenta, conforme a região do entrevistado, como as estruturas de governança se apresentam para as relações no SAG do leite e os atributos identificados. Como se verifica nesse quadro, de forma predominante, os produtores e processadores ouvidos no Paraná, com exceção do processador 4, que integralizou a produção, indicaram a predominância da governança híbrida 
para a compra e venda do leite in natura, em todos as regiões estudadas, por contratos informais ou contratos formais. A contratação formal, por sua vez, foi indicada, apenas, por um grupo de produtores entrevistados, pertencentes à região Centro-Oriental, estes integrantes de uma cooperativa. E apenas o representante de uma cooperativa confirmou a utilização de contrato formal com os produtores, específico para o leite, paralelo à adesão ao estatuto da cooperativa.

Quadro 2 - Descrição das características das relações por região pela ótica da ECT

\begin{tabular}{|c|c|c|c|}
\hline \multirow[b]{2}{*}{ REGIÕES } & \multicolumn{3}{|c|}{ CARACTERÍSTICAS DAS RELAÇÕES } \\
\hline & $\begin{array}{c}\text { Tipo de } \\
\text { governança }\end{array}$ & Atributos de transação & $\begin{array}{c}\text { Influência do Ambiente } \\
\text { Institucional }\end{array}$ \\
\hline $\begin{array}{l}\text { Norte Central; } \\
\text { Norte Pioneiro }\end{array}$ & $\begin{array}{l}\text { Híbrida: } \\
\text { acordo } \\
\text { informal }\end{array}$ & $\begin{array}{l}\text { Especificidade locacional e } \\
\text { temporal. Frequência recorrente. } \\
\text { Incerteza ambiental (preço) e } \\
\text { comportamental (continuidade da } \\
\text { relação). }\end{array}$ & $\begin{array}{l}\text { Indicadores de qualidade: IN } 62 \\
\text { Preço: Conseleite. }\end{array}$ \\
\hline Noroeste & $\begin{array}{l}\text { Híbrida: } \\
\text { acordo } \\
\text { informal }\end{array}$ & $\begin{array}{l}\text { Especificidade locacional e } \\
\text { temporal. Frequência recorrente. } \\
\text { Incerteza ambiental (preço) e } \\
\text { comportamental (continuidade da } \\
\text { relação). }\end{array}$ & $\begin{array}{l}\text { Indicadores de qualidade: IN } 62 . \\
\text { Preço: Conseleite + bonificação em } \\
\text { alguns indicadores de qualidade. }\end{array}$ \\
\hline $\begin{array}{l}\text { Centro } \\
\text { Ocidental }\end{array}$ & $\begin{array}{l}\text { Híbrida: } \\
\text { acordo } \\
\text { informal }\end{array}$ & $\begin{array}{l}\text { Especificidade locacional e } \\
\text { temporal. Frequência recorrente. } \\
\text { Incerteza ambiental (preço) e } \\
\text { comportamental (continuidade da } \\
\text { relação). }\end{array}$ & $\begin{array}{l}\text { Indicadores de qualidade: IN } 62 . \\
\text { Preço: Conseleite + bonificação em } \\
\text { alguns indicadores de qualidade. }\end{array}$ \\
\hline $\begin{array}{l}\text { Oeste; } \\
\text { Sudoeste }\end{array}$ & $\begin{array}{l}\text { Híbrida: } \\
\text { acordo } \\
\text { informal }\end{array}$ & $\begin{array}{l}\text { Especificidade locacional, temporal } \\
\text { e dedicada. Frequência recorrente. } \\
\text { Incerteza ambiental (preço) e } \\
\text { comportamental (continuidade da } \\
\text { relação pelo processador). }\end{array}$ & $\begin{array}{l}\text { Indicadores de qualidade: IN } 62 \text {. } \\
\text { Preço: Conseleite + bonificação } \\
\text { ou penalização nos indicadores de } \\
\text { qualidade. }\end{array}$ \\
\hline $\begin{array}{l}\text { Centro- } \\
\text { Oriental }\end{array}$ & $\begin{array}{l}\text { Híbrida: } \\
\text { contrato } \\
\text { formal }\end{array}$ & $\begin{array}{l}\text { Especificidade locacional, } \\
\text { temporal, física, humana, dedicada } \\
\text { e de marca. Frequência recorrente. } \\
\text { Incerteza ambiental (oscilação do } \\
\text { mercado consumidor). }\end{array}$ & $\begin{array}{l}\text { Indicadores de qualidade: IN } 62 \\
+ \text { tabela própria de indicadores } \\
\text { de qualidade. Preço: Cepea + } \\
\text { bonificação ou penalização por faixas } \\
\text { de desempenho nos indicadores de } \\
\text { qualidade. }\end{array}$ \\
\hline Centro-Sul & $\begin{array}{l}\text { Híbrida: } \\
\text { acordo } \\
\text { informal }\end{array}$ & $\begin{array}{l}\text { Especificidade locacional (linhas } \\
\text { padrão e da qualidade); temporal, } \\
\text { física e dedicada. } \\
\text { recorrente. Incerteza ambiental } \\
\text { (preço) e comportamental } \\
\text { (continuidade da relação pelo } \\
\text { processador). }\end{array}$ & $\begin{array}{l}\text { Indicadores de qualidade: IN } 62 . \\
\text { Preço: Cepea + bonificação ou } \\
\text { penalização nos indicadores de } \\
\text { qualidade + bônus de fidelidade (a } \\
\text { cada ano completo de acordo). }\end{array}$ \\
\hline
\end{tabular}

Fonte: Elaborado pelos autores a partir dos dados primários.

Considera-se que, pelas informações apresentadas, existe um certo alinhamento entre esses atributos e a estrutura de governança utilizada. Os produtores indicaram que a partir do acordo há maior facilidade para a troca de processadores, o que foi ratificado por eles. Esse aspecto demonstra a busca continuada de melhor remuneração por parte do produtor. O produtor 20 confirma essa prática: "Acordo verbal, conversa e acerto. A maioria é assim. Aqui nesta região são bem poucos os que fazem contrato, não é viável mais, por causa da variação de preço?. Essa forma de relação indica a busca 
pelo produtor da melhor distribuição de valor na cadeia, e define instabilidade para a relação. Essa condição justifica a incerteza do segmento processador quanto à obtenção de volume e regularidade, e do produtor quanto à continuidade na relação e na formalidade dos direitos.

Essa condição, entretanto, parece satisfazer produtores e processadores, que se amparam no regramento formal e organismos privados para obter maior estabilidade nas transações. Observa-se, nesse caso, que a contratação informal não garante todos os direitos transacionados e não elimina a necessidade de capital reputacional (BARZEL, 2005). Essa situação gera custos de transação ex ante, dado que o investimento nas relações se estabelece como mecanismo de redução de incerteza, influenciando no design do acordo ex ante e velocidade do investimento e não reduz a necessidade de negociação ex post. O produtor 30 ratifica: "Geralmente é um compromisso verbal, mas estou mudando para um contrato escrito, porque assim tenho alguma garantia. Por enquanto está tudo bem, mas se acontece algo? O contrato vai estabelecer garantia que vai manter o combinado, o contrato me confirma como fornecedor".

A condução dessa análise por intermédio dos pressupostos da TCM oferece uma explicação complementar para justificar a estrutura adotada para coordenar as transações e a forma das relações construídas por esses agentes. Evidenciou-se nas relações de compra e venda que as partes transacionam as dimensões mensuráveis, que por sua vez carregam os direitos de propriedade existentes no produto. É possível, portanto, considerar que o arranjo adotado (contrato formal ou informal) seja capaz de proteger o valor alocado no ativo transacionado, garantindo a maior parcela desses direitos (CALEMAN; SPROESSER; ZYLBERSZTAJN, 2008), dadas as regras definidas pela IN 62. Observa-se, no entanto, que essa mensuração ocorre, em sua maioria, pelo lado do processador e a fragilidade da contratação informal propicia condições para que os custos de transação se apresentem, gerando ineficiência. Novamente, contratos informais geram enforcement informal e demandam negociação para solução de disputas ex post, contribuindo para a manutenção desse ambiente de incerteza (WILLIAMSON, 1985; BARZEL, 2005).

Caleman et al. (2006) afirmam que, na TCM, a escolha da governança apresenta-se mais dinâmica que na ECT, pois depende do grau de conhecimento da mensuração dos atributos da transação, ou seja, da distribuição de informação. Desse modo, a coordenação poderá ser alterada à medida que os atributos se tornam mais fáceis ou mais difíceis de mensurar. Ao abordar o SAG do leite por meio do suporte teórico da TCM foi possível esclarecer quais dimensões estão associadas às transações do ativo (leite) realizadas entre os segmentos produtor e processador, e a eficiência relativa a elas. Isso está determinado, a priori, na IN 62, na qual se define as dimensões físicas, microbiológicas e químicas do leite, que são passíveis de medição e agregação de valor monetário na transação. O processador 1 afirma: "As mesmas exigências são para todos os produtores, [...]. A gente segue a Norma 62". Essa posição é confirmada pelo produtor 10: "Mesmo sem contrato, exige quantidade, qualidade, higiene e sanidade dos animais. Tem que ter responsabilidade sobre o leite, se manter dentro das normas. Se não tiver qualidade, você é penalizado, mas eles determinam o preço". 
Além disso, ratifica-se que a estrutura de governança na forma híbrida, formal ou informal, se justifica dado que as dimensões são passíveis de mensuração, ratificando-se o racional proposto por Barzel (2005). A análise teórica, portanto, baseada nas proposições da TCM, possibilitou esclarecer quais informações sobre o leite efetivamente respaldam e efetivam as transações realizadas no SAG.

O Quadro 3, identifica, por região, as dimensões mensuráveis do leite transacionado, bem como a respectiva estrutura de proteção adotada, com base nos pressupostos da TCM.

Quadro 3 - Dimensões mensuráveis e mecanismos de controle pela ótica da TCM

\begin{tabular}{|c|l|l|}
\hline \multirow{2}{*}{ REGIÕES } & \multicolumn{1}{|c|}{ CARACTERÍSTICAS DAS RELAÇÕES } \\
\cline { 2 - 4 } $\begin{array}{c}\text { Norte Central; } \\
\text { Norte Pioneiro }\end{array}$ & $\begin{array}{l}\text { Físicas: volume produzido. Microbiológicas: acidez e } \\
\text { presença de antibiótico; Químicas: não relatadas. }\end{array}$ & $\begin{array}{l}\text { Contrato informal e } \\
\text { relações de longo prazo. }\end{array}$ \\
\hline Noroeste & $\begin{array}{l}\text { Físicas: volume produzido. Microbiológicas: acidez, } \\
\text { presença de antibiótico e água, CCS e CBT. Químicas: } \\
\text { gordura. }\end{array}$ & $\begin{array}{l}\text { Contrato informal e } \\
\text { relações de longo prazo. }\end{array}$ \\
\hline Centro Ocidental & $\begin{array}{l}\text { Físicas: volume produzido. Microbiológicas: acidez, } \\
\text { presença de antibiótico e água, CCS e CBT. Químicas: } \\
\text { gordura. }\end{array}$ & $\begin{array}{l}\text { Contrato informal e } \\
\text { relações de longo prazo. }\end{array}$ \\
\hline Oeste; Sudoeste & $\begin{array}{l}\text { Físicas: volume produzido. Microbiológicas: acidez, } \\
\text { presença de antibiótico e água, CCS e CBT. Químicas: } \\
\text { gordura e proteína. }\end{array}$ & $\begin{array}{l}\text { Contrato informal } \\
\text { relações de longo prazo. }\end{array}$ \\
\hline Centro-Oriental & $\begin{array}{l}\text { Físicas: volume produzido, infraestrutura. } \\
\text { Microbiológicas: acidez, presença de antibiótico e água, } \\
\text { CCS e CBT. Químicas: gordura e proteína. Medições dos } \\
\text { indicadores por faixa de desempenho. }\end{array}$ & $\begin{array}{l}\text { Contrato formal } \\
\text { relações de longo prazo. }\end{array}$ \\
\hline Centro-Sul & $\begin{array}{l}\text { Físicas: volume produzido. Microbiológicas: acidez, } \\
\text { presença de antibiótico e água, CCS e CBT. Químicas: } \\
\text { gordura. }\end{array}$ & $\begin{array}{l}\text { Contrato informal e } \\
\text { relações de longo prazo. }\end{array}$ \\
\hline
\end{tabular}

Fonte: Elaborado pelos autores a partir dos dados primários.

Assim, a forma como a governança híbrida coordena as relações, amparada pela mensuração das dimensões do ativo, conforme propõe Barzel (1997, 2005), pode diminuir custos de transação e garantir os direitos de propriedade. Isso gera eficiência, justificando desse modo a bilateralidade e a dependência dos segmentos por esse tipo de arranjo, interessando sua continuidade, seja por força contratual (formal ou informal) ou por confiança e reputação, ou ambas, como visto na região Centro-Oriental do Estado. O contrato informal, no entanto, embora seja a prática na maioria das regiões do Estado, indica condição de ineficiência. Embora a remuneração seja amparada em dimensões mensuráveis e o preço-base estimado por organismo institucional externo, o que oferece redução nas incertezas quanto ao valor a receber, a não formalidade de compromissos e formas de resolução de conflitos não estimulam os investimentos qualitativos e quantitativos.

Ao se confrontar as regiões com as expectativas de investimentos dos produtores entrevistados, observa-se que produtores com baixa tecnificação, os quais, conforme dados do Ipardes (INSTITUTO..., 2010), representam 80\% dos produtores do Estado, apresentam baixa ou quase nenhuma intenção de investimento (Quadro 4). 
Quadro 4 - Principais investimentos realizados ou planejados dos produtores do SAG do leite por região

\begin{tabular}{|c|c|c|c|}
\hline \multirow[b]{2}{*}{$\begin{array}{c}\text { Regiões do } \\
\text { Paraná }\end{array}$} & \multicolumn{3}{|c|}{ PRODUTORES } \\
\hline & $\begin{array}{c}\text { Baixa } \\
\text { tecnificação }\end{array}$ & Média tecnificação & Alta tecnificação \\
\hline $\begin{array}{l}\text { Norte e } \\
\text { Noroeste }\end{array}$ & Não há previsão & $\begin{array}{l}\text { Aquisição de vacas; ordenha } \\
\text { mecânica; adubação e irrigação } \\
\text { no pasto; sistema de fosso } \\
\text { de ordenha, forrageira com } \\
\text { vagão; gerar energia própria na } \\
\text { propriedade. }\end{array}$ & $\begin{array}{l}\text { Barracão para compostagem e } \\
\text { composto de baia para cada vaca; } \\
\text { melhoramento da genética das } \\
\text { vacas; tratamento de resíduos, } \\
\text { aproveitamento da água da chuva } \\
\text { com cisternas; abrigo para as } \\
\text { bezerras. }\end{array}$ \\
\hline Centro e Sul & $\begin{array}{l}\text { Barracão para } \\
\text { as vacas e fosso } \\
\text { de ordenha } \\
\text { azulejado. }\end{array}$ & $\begin{array}{l}\text { Aumentar o plantel com aquisição } \\
\text { de vacas de raça; melhoramento } \\
\text { genético e inseminação; melhorar } \\
\text { sala de ordenha e confinamento } \\
\text { do gado; adubação e irrigação } \\
\text { do pasto; mecanização para o } \\
\text { trato do gado; silagem; plantio } \\
\text { de eucaliptos para sombra dos } \\
\text { animais. }\end{array}$ & $\begin{array}{l}\text { Compra de animais e inseminação; } \\
\text { construção ou ampliação de } \\
\text { barracão para novilhas e vacas em } \\
\text { anestro, novos silos, melhoria na } \\
\text { sala de leite; trincheira em concreto. }\end{array}$ \\
\hline $\begin{array}{c}\text { Oeste e } \\
\text { Sudoeste }\end{array}$ & Não há previsão & $\begin{array}{l}\text { Aumento de animais em } \\
\text { lactação; aumento dos galpões } \\
\text { de alimentação; tanques de } \\
\text { retenção de resíduos. }\end{array}$ & Não* \\
\hline Leste & Não* & $\begin{array}{l}\text { Melhores acomodações para } \\
\text { as vacas em confinamento; } \\
\text { estrutura física para silagem. }\end{array}$ & $\begin{array}{l}\text { Construção e ampliação de barracão } \\
\text { de leite; melhorar equipamentos; } \\
\text { controle individual automatizado } \\
\text { por vaca; tratamento de resíduos } \\
\text { sólidos; instalação de mais } \\
\text { ventiladores para o conforto animal; } \\
\text { importação do equipamento para } \\
\text { ordenha robotizada. }\end{array}$ \\
\hline
\end{tabular}

* Não houve produtores entrevistados na tecnificação correspondente.

Fonte: Elaborado pelos autores a partir dos dados primários.

Ao se considerar o Quadro 4 pode-se induzir que os produtores de baixa e média tecnificação são mais reticentes em fazer investimentos na atividade, o que pode ser associado à informalidade das relações. Os produtores de média tecnificação procuram investir em itens que thes tragam retorno rápido e seguro, associados à quantidade produzida, portanto de fácil mensuração. Já os produtores de alta tecnificação apresentam um produto com qualidade superior à recomendada pela IN 62. Seus indicadores de qualidade são mais rigorosos e estão passíveis de descontos em todos os itens, porém são monitorados e suas bonificações também são as mais altas praticadas.

Dessa forma, na análise do SAG do leite paranaense, constatou-se que no ambiente institucional o regramento formal é representado pela IN 62, enquanto que o informal é influenciado, majoritariamente, pelos referenciais de valor do Conseleite. A presença desses fatores nas microinstituições da cadeia produtiva do leite é decisiva no delineamento das transações do produto realizadas por produtores e processadores do SAG, nas diferentes regiões pesquisadas. 
Foi identificado, por intermédio da pesquisa, que, na análise das relações formais existentes entre produtores e processadores (sob inspeção), a maioria dos entrevistados é produtor rural há mais de 20 anos, e que demonstram ter conhecimento e experiência em transacionar o leite. $E$, apesar de apresentarem, na perspectiva da relação, níveis de tecnificação diferentes, preferem manter, com maior ou menor grau de dependência, suas relações com os processadores seguindo os procedimentos formais, dadas as especificidades locacional e temporal do leite, a frequência das transações e a diminuição das incertezas pelas contingências e oscilações do mercado consumidor e do preço praticado. Dito de outra forma, são encontrados na transação todos os atributos pressupostos pela ECT, nos termos propostos por Williamson (1985), aos quais se alinham as relações contratuais existentes (contratos formais ou informais). Isso dá maior respaldo aos futuros investimentos específicos, incrementando a produção e os ganhos em volume e qualidade.

Tanto os processadores como os produtores entrevistados afirmaram ser a governança híbrida a mais viável devido à influência que o ambiente institucional exerce nas transações. Essa governança justifica o desempenho dos arranjos no SAG e sua predominância no Paraná, mesmo que os acordos informais, frequentes na maioria das relações, não possam garantir de forma plena os direitos econômicos das partes. Isso se dá devido à existência do risco de apropriação indevida e sem direito à reparação, dados os mecanismos informais de enforcement.

Por conta disso, intensifica-se o papel da IN 62, que muito provavelmente seja a responsável pela fácil mensuração e verificação das dimensões do leite e, ainda que incorram em custos de mensuração, tornam os direitos reconhecidos e remunerados na relação (direitos de propriedade). Mesmo nos acordos informais são essas análises que garantem e protegem os direitos econômicos, definidos por Barzel (2005), dos produtores. Em contrapartida, a governança híbrida por contratos formais (como os encontrados na região Centro-Oriental do Estado) é capaz de garantir significativamente os direitos de propriedade legais dos contratantes e, conforme observado, estimular investimentos, com impacto no nível de tecnificação do produtor. Esse é um aspecto fundamental para o segmento processador que precisa de volume e qualidade para garantir seu desempenho. A relação contratual formal reduz as incertezas quanto à quantidade e os níveis de sólidos necessários para seu melhor desempenho, o que é limitado pelos contratos informais, que predominam no Estado.

Com relação aos demais tipos de governança associados a ECT (mercado e hierarquia), esses foram pouco observados no SAG paranaense. A governança de mercado ocorre quando produtores, por algum motivo, não têm o leite coletado pelo comprador contratado, e para não perder o produto e a renda negociam com (qualquer) terceiro. Essa estrutura de governança também se apresenta dentro do próprio segmento processador, quando o processador adquire leite de outro processador. Já a governança hierárquica foi encontrada em somente um laticínio pesquisado e, considerando o encerramento de suas atividades e a aversão à ideia pelos demais produtores e processadores, parece que realmente esse tipo de governança não é viável nas condições atuais do ambiente institucional, em razão dos custos e exigências inerentes, notadamente quanto ao processamento na propriedade. Pode-se considerar, no entanto, que a hie- 
rarquia está subjetivamente presente no discurso de alguns produtores pertencentes a cooperativas, que tomam também por seu negócio, todo o processo industrial e comercial da cooperativa, porém na prática são regidos por acordos ou contratos.

\section{CONCLUSÃO}

Neste estudo tratou-se das estruturas de governanças no SAG de leite no Paraná, à luz das Teorias do Custo de Transação e de Mensuração, e do nível de tecnificação dos produtores envolvidos, por região. Para tanto foram utilizados procedimentos qualitativos e pesquisa do tipo descritiva, com a coleta de dados envolvendo entrevistas com produtores e processadores, nas diversas regiões produtoras do Estado.

Concluiu-se que em todas as regiões citadas, com exceção da Centro-Oriental, a governança das transações envolvendo produtores e processadores se dá pela forma híbrida por contrato informal, graças à influência exercida e assegurada pelos parâmetros da IN 62 e à referência para o preço praticado, oferecido pelo Conseleite ou Cepea. Esses parâmetros, somados à confiança e à reputação, minimizam os custos de transação e oferecem garantias aos direitos econômicos das partes, viabilizando esse tipo de estrutura de governança. A condição de enforcement informal, entretanto, limita sua capacidade de garantir direitos de propriedade e estimular a tecnificação de produtores. Isso foi constatado ao se relacionar nível de tecnificação, intenção de investimento e estrutura de governança. Como consequência a incerteza quantos aos níveis qualitativos e quantitativos no fornecimento gera gargalos competitivos no segmento processador.

A única região em que se identificou a forma híbrida com uso de contratos formais foi a região Centro-Oriental. Essa região caracteriza-se por responder pelos maiores índices de produtividade no Estado e no Brasil e por elevados níveis de tecnificação dos produtores. Identificou-se que a utilização de contratos formais nas transações entre processadores e produtores oferece garantias reais dos direitos de propriedade, estimulando investimentos. Para esses, a mensuração das dimensões é mais rigorosa, indo além das exigências da normativa, porém o preço ofertado e os adicionais de remuneração são mais satisfatórios entre todos os produtores pesquisados, além de envolver disponibilização de informação. Essa condição eleva a motivação para a realização de mais investimentos na atividade para os dois segmentos.

De forma positiva, a pesquisa mostrou a influência da estrutura de governança, não apenas na eficiência das relações, mas, também, no desempenho do SAG de leite no Paraná, dado que as estruturas vigentes indicaram influência nas decisões relacionadas à tecnificação entre os produtores pesquisados. Embora a forte presença do ambiente institucional estabilize as relações, orientando a distribuição de valor, e indique os caminhos para o desempenho do SAG, as condições de informalidade na contratação reduzem a disposição ao investimento, dado o residual de incerteza gerado, o que ratifica a necessidade da contratação formal.

Foi identificada a forte conexão entre o alinhamento das estruturas de governança e a obtenção de maior tecnificação dos produtores, notadamente pelo estimulo ao investimento, posto que a maior formalidade na transação propicia redução na incerteza. Essa constatação serve para orientar políticas públicas e privadas na definição do regramento a ser adotado na relação entre o segmento produtor e processador, para a formalização das suas trocas, e sua influência no desempenho da cadeia como um todo. 
Os resultados indicam, por sua vez, que um estudo com maior profundidade nas regiões pesquisadas pode detalhar as especificidades regionais e orientar políticas públicas para o setor, de forma particular quanto à contratação. Esse parece ser um campo de pesquisa a ser explorado com efetiva contribuição à redução da assimetria de desempenho entre as regiões. Para a academia, analisar com maior profundidade a relação entre o nível de tecnificação e a contratação formal, buscando ouvir um maior número de produtores e processadores, bem como agentes do ambiente institucional, de forma a obter maior amparo às propostas de políticas, faz-se necessário. Além disso, analisar como o regramento e o enforcement informal afetam as decisões de investimento, tanto no segmento produtor quanto no processador, apresenta-se como problema não explorado neste estudo, e que precisa ser debatido visando a indicar caminhos para maior formalidade e eficiência na coordenação no SAG.

\section{REFERÊNCIAS}

ALVES, D. R. Industrialização e comercialização do leite de consumo no Brasil. In: MADALENA, F. E.; MATOS, L. L. de.; HOLANDA JR., E. (Ed.). Produção de leite e sociedade. Belo Horizonte: FEPMVZ, 2001. p. 75-83.

ALMEIDA, E. F. L. Aspectos sociais da produção de leite no Brasil. In: MADALENA, F. E. MATOS, L. L.; HOLANDA JR., E. (Ed.). Produção de leite e sociedade. Belo Horizonte: FEPMVZ, 2001. p. 117-124.

AZEVEDO, P. F. Nova economia institucional: referencial geral e aplicações para a agricultura. Agricultura em São Paulo, v. 47, n. 1, p. 33-52, 2000.

Determinantes das estruturas de governança: integração vertical e formas de contratação. In: BRAGA, M. J.; TEIXEIRA, E. (Org.). Defesa da concorrência e poder de mercado no agronegócio. 1. ed. Viçosa: Universidade Fed. de Viçosa, 2005. p. 187-224. V. 1.

BANCO NACIONAL DE DESENVOLVIMENTO ECONÔMICO E SOCIAL (BNDES). Produção leiteira no Brasil. BNDES Setorial, n. 37, Rio de Janeiro, p. 371-398, mar. 2013.

BANKUTI, S. M. S. Análise das transações e estruturas de governança na cadeia produtiva do leite no Brasil: a França como referência. Tese (Doutorado em Engenharia de Produção) - Universidade Federal de São Carlos, SP, 2007.

BARDIN, L. Análise de conteúdo. Lisboa, Portugal: Edições 70, 1979.

BARZEL, Y. Measurement cost and the organization of markets. Journal of Law and Economics, p. 27-48, apr. 1982.

Economic analysis of property right. 2. ed. Cambridge: Cambridge University Press, 1997.

A Theory of Organizations: to supersede the theory of the firm. [S.I.: s.n.], 2001.

Organizational forms and Measurements Costs. In: ANNUAL CONFERENCE OF THE INTERNATIONAL SOCIETY FOR THE NEW INSTITUTIONAL ECONOMICS, Massachusetts, 2002.

Organizational and Measurement Costs. Mohr Siebeck: Journal of Institutional and Theoretical Economics, 2005.

CALEMAN, S. M. Q. et al. Mecanismos de governança em sistemas agroalimentares - um enfoque nos custos de mensuração. Revista de Economia e Agronegócio, vol. 4, n. 2, p. 219-240, 2006.

CALEMAN, S. M. Q.; SPROESSER, R. L.; ZYLBERSZTAJN, D. Measurement Costs and Agribusiness Governance: a multiple case study applied to beef agrichain. Organizações Rurais \& Agroindustriais, Lavras, v. 10, n. 3, p. 359-375, 2008.

CAMPOS, K. C.; PIACENTI, C. A. Agronegócio do leite: cenário atual e perspectivas. In: CONGRESSO DA SOBER, 45., 2007. Londrina, 22 a 25 de julho de 2007.

CARVALHO, T. B. et al. Estratégia e cenários de consumo de leite no Brasil. SEMEAD - SEMINÁRIO DE ADMINISTRAÇÃO, 16. São Paulo, 2013.

COASE, R. H. The Nature of the Firm. Econômica, v. 4, p. 386-405, 1937.

COMMONS, J. The problem of correlating law, economics, and ethics. Wisconsin Law Review, n. 8, p. 3.026, 1932.

CROOK, T. R. et al. Organizing around transaction costs: what have we learned and where do we go from here? Academy of Management Perspectives, 27 (1), 63-79, 2013.

DÜRR, J. W. Como produzir leite de qualidade. 4. ed. Brasília: Senar, 2012. 
FARINA, E. M. M. Q. Padronização em sistemas agroindustriais. Estudo de Caso. SEMINÁRIO PENSA DE AGRIBUSINESS, 9., São Paulo, 1999.

FERRARI D. L. et al. Agricultores familiares, exclusão e desafios para inserção econômica na produção de leite em Santa Catarina. Informações Econômicas, SP, v. 35, n. 1, jan. 2005.

FOSS, K.; FOSS, N. J. Assets, Attributes and Ownership. Journal of the Economics of Business, v. 8, n. 1, p. 19-37, 2001.

INSTITUTO BRASILEIRO DE GEOGRAFIA E ESTATÍsTICA (IBGE). Censo Agropecuário 2006: Brasil, grandes regiões e unidades da federação. Rio de Janeiro, 2006. Disponível em: <http://www.ibge.gov.br/home/ estatistica/economia/agropecuaria/censoagro/>. Acesso em: 20 out 2015.

Indicadores IBGE: estatística da produção pecuária. Março, 2015. Disponível em: <http://www. ibge.gov.br/home/estatistica/indicadores/agropecuaria/producaoagropecuaria/abate-leite-couro-ovos_201404_publ_completa.pdf>. Acesso em: 25 abr. 2015.

INSTITUTO PARANAENSE DE DESENVOLVIMENTO ECONÔMICO E SOCIAL (Ipardes). Instituto Paranaense de Assistência Técnica e Extensão Rural. Caracterização da indústria de processamento e transformação do leite no Paraná. Curitiba: Ipardes, 2010. Disponível em: <http://www.ipardes.gov.br/pdf/caracterizacao_industria_leite.pdf>. Acesso: 15 dez. 2015.

JANK, M. S.; GALAN, V. B. Competitividade do sistema agroindustrial do leite no Brasil. In: JANK, M. S.; FARINA, E. M. Q.; GALAN, V. B. O agribusiness do leite no Brasil. São Paulo: Milkbizz, p. 41-100, 1999.

JANK, M. S.; FARINA, E. M. Q.; GALAN, V. B. O agribusiness do leite no Brasil. São Paulo: Milkbizz, 1999.

KLEIN, P. G. New Institutional Economics. Encyclopedia of Law and Economics. Georgia: University of Georgia, 1999.

MADALENA, F. E. A cadeia do leite no Brasil. In: MADALENA, F. E.; MATOS, L. L.; HOLANDA JR, E. (Ed.). Produção de leite e sociedade. Belo Horizonte: FEPMVZ, 2001. p. 1-26.

MINISTÉRIO DA AGRICULTURA, PECUÁRIA E ABASTECIMENTO (Mapa). Plano mais pecuária. Brasília: Mapa; ACS. Disponível em: <http://www.agricultura.gov.br/arq_editor/file/Ministerio/Publicacao_ v2.pdf>. Acesso em: 15 dez. 2015.

2002.

Instrução Normativa n. 51, de 18 de setembro de 2002. Diário Oficial da União, Brasília, 20 set.

Instrução normativa n. 62, de 29 de dezembro de 2011. Diário Oficial da União, 30 dez. 2011.

MILKPOINT. IBGE: produção de leite cresceu 2,7\% em 2014. Disponível em: <http://www.milkpoint.com. br/cadeia-do-leite/giro-lacteo/ibge-producao-de-leite-cresceu-27-em-2014-sul-tornouse-a-maior-regiao-produtora-97326n.aspx>. Acesso em: 11 jan. 2016.

NORTH, D. Institutions, institutional change and economic performance. Cambridge: Cambridge University Press, 1990.

Institutions. The Journal of Economic Perspectives, vol. 5, n. 1, p. 97-112, 1991.

OKANO, M. T.; VENDRAMETTO, O.; SANTOS, O. S. dos. Como a organização dos produtores de leite da região de fartura em uma rede de empresas beneficiou a produtividade leiteira. CONGRESSO NACIONAL DE EXCELÊNCIA EM GESTÃO, 6., Niterói, RJ, 2010.

PONDÉ, J. L.; FAGUNDES, J.; POSSAS, M. Custos de transação e políticas de defesa da Concorrência. Rev. de Economia Contemporânea, UFRJ, v. 2, p. 115-136, jul./dez. 1997.

RIBEIRO, R. Informalidade no mercado do leite. Disponível em: <https://www.scotconsultoria.com.br/leite/mercado-leite/165/informalidade-no-mercado-do-leite.htm>. Acesso em: 10 ago. 2016.

RICHARDSON, R. J. Pesquisa social: métodos e técnicas. 3. ed. 14. reimp. São Paulo: Atlas, 2012.

SECRETARIA DE ESTADO DA AGRICULTURA E DO ABASTECIMENTO (Seab). Departamento de Economia Rural (Deral). Análise da conjuntura agropecuária: 2013/2014. Disponível em: <http://www.agricultura. pr.gov.br/arquivos/File/deral/Prognosticos/leite_2013_14.pdf>. Acesso em: 5 fev. 2016.

UNITED STATES DEPARTMENT OF AGRICULTURE (Usda). Dairy: world markets and trade. 2015. Disponível em: <http://apps.fas.usda.gov/psdonline/circulars/dairy.pdf>. Acesso: 1o fev. 2016.

WILLIAMSON, O. E. The economic institutions of capitalism - firms, markets, relational contracting. New York: The Free Press, 1985.

The mechanisms of governance. Oxford: Oxford University Press, 1996.

2007.

Transaction cost economics: an introduction. Discussion paper. Berkeley: University of California,

ZOCCAL, R. et al. A nova pecuária leiteira brasileira. In: BARBOSA, S. B. P., BATISTA, A. M. V., MONARDES, H. Congresso Brasileiro de Qualidade do Leite, 3. Recife: CCS Gráfica e Editora, 2008. p. 85-95. V. 1. 
ZYLBERSZTAJN, D. Papel dos contratos na coordenação agroindustrial: um olhar além dos mercados. RER, Rio de Janeiro, vol. 43, n. 3, p. 385-420, jul./set. 2005a.

Measurement costs and governance: bridging perspectives of transaction cost economics. In: International Society for the New Institutional Economics - Isnie. Barcelona-Espanha, 2005b.

ZYLBERSZTAJN, D.; GIORDANO, S. R. Coordenação e governança de sistemas agroindustriais. In: ZYLBERSZTAJN, D.; NEVES, M. F.; CALEMAM, S. M. Q. (Org.). Gestão de sistemas de agronegócio. São Paulo: Atlas, 2015. p. 1-22. 